\title{
Meningococcal conjugate vaccines: optimizing global impact
}

\author{
This article was published in the following Dove Press journal: \\ Infection and Drug Resistance \\ 2I September 201 I \\ Number of times this article has been viewed
}

\author{
Andrew Terranella ${ }^{1,2}$ \\ Amanda Cohn ${ }^{2}$ \\ Thomas Clark ${ }^{2}$ \\ 'Epidemic Intelligence Service, \\ Division of Applied Sciences, \\ Scientific Education and Professional \\ Development Program Office, \\ ${ }^{2}$ Meningitis and Vaccine Preventable \\ Diseases Branch, National Center \\ for Immunization and Respiratory \\ Diseases, Centers for Disease \\ Control and Prevention, Atlanta, \\ GA, USA
}

\begin{abstract}
Meningococcal conjugate vaccines have several advantages over polysaccharide vaccines, including the ability to induce greater antibody persistence, avidity, immunologic memory, and herd immunity. Since 1999, meningococcal conjugate vaccine programs have been established across the globe. Many of these vaccination programs have resulted in significant decline in meningococcal disease in several countries. Recent introduction of serogroup A conjugate vaccine in Africa offers the potential to eliminate meningococcal disease as a public health problem in Africa. However, the duration of immune response and the development of widespread herd immunity in the population remain important questions for meningococcal vaccine programs. Because of the unique epidemiology of meningococcal disease around the world, the optimal vaccination strategy for long-term disease prevention will vary by country.
\end{abstract}

Keywords: conjugate vaccine, meningitis, meningococcal vaccine, meningococcal disease

\section{Introduction}

Though the incidence is relatively low, many industrialized countries prioritize meningococcal disease prevention due to its rapid onset, fulminant nature, high case fatality ratio, and long-term sequelae. The advent of conjugate vaccines against common meningococcal serogroups has proven a major advancement in controlling meningococcal disease. The UK was the first country to launch a national meningococcal conjugate vaccination program in 1999 using a serogroup $\mathrm{C}$ vaccine, resulting in a dramatic decline in serogroup $C$ disease. ${ }^{1}$ In contrast to industrialized countries, the burden of meningococcal disease in the sub-Saharan African "meningitis belt" is large and frequent epidemics occur that are disruptive to the public health infrastructure. ${ }^{2}$ The development of a safe, effective, affordable conjugate vaccine against serogroup A meningococcal disease is a tremendous advance that has the potential to eliminate epidemic meningococcal disease as a public health concern in Africa.

Meningococcal conjugate vaccines were developed to overcome the limitations of polysaccharide vaccines. The defining characteristic of the protein-polysaccharide conjugate vaccine is the ability to induce a T-cell dependent immune response. The resulting immunologic benefits include priming for a memory response, antibody avidity maturation, development of protective antibodies in young children, and reduction of nasopharyngeal carriage. Conjugate meningococcal vaccines have the potential to protect unvaccinated age groups in a population through herd immunity. This review will focus on meningococcal conjugate vaccines and the impact of vaccination programs on meningococcal epidemiology.
Correspondence: Andrew Terranella National Center for Immunization and Respiratory Diseases, 1600 Clifton Rd, MS C-09, Atlanta, GA 30333, USA

Tel +l 4046394467

Email aqtI@cdc.gov 


\section{Meningococcal disease}

Meningococcal disease most commonly presents as a bloodstream infection or meningitis, with other localized infections such as pneumonia presenting less commonly. Bloodstream infection can occur with or without other localized infection. Meningococcemia, or fulminant bloodstream infection, occurs in approximately $20 \%$ of patients with bacteremia and results from rapid proliferation of meningococci in the blood. The overall case fatality ratio for meningococcal disease is approximately $10 \%-15 \%$, and is as high as $25 \%-30 \%$ in patients with meningococcemia. Disease onset is often rapid, and death may occur within 24 hours in the absence of antimicrobial therapy. Globally, there are approximately 614,000 cases annually with the highest incidence in sub-Saharan Africa (10-25 per 100,000). The incidence in Canada, the US, and Europe varies substantially by country, ranging from 0.35 per 100,000 to three per 100,000 persons per year. ${ }^{3}$ Incidence also varies by age with infants at greatest risk and a second peak in incidence observed among adolescents in most industrialized countries.

Neisseria meningitidis is a Gram-negative, encapsulated diplococcus that exclusively infects humans. Thirteen distinct serogroups have been identified based on their capsular polysaccharide, with serogroups A, B, C, Y, and W-135 accounting for nearly all disease. Serogroup distribution varies globally, with serogroup A predominant in Africa, and serogroups B, C, and Y observed in Asia, Europe, and the Americas with variable frequency. ${ }^{4}$ Age-specific incidence also varies. In the US, serogroup B accounts for approximately $65 \%$ of infant disease, while serogroups $\mathrm{C}$ and $\mathrm{Y}$ cause the majority of disease in adolescents and serogroup Y predominates in the elderly. ${ }^{5}$

Neisseria meningitidis is a transient commensal of the human nasopharynx. Acquisition of the organism and colonization of the nasopharynx is necessary for the development of disease, but not sufficient. In the majority of cases, carriage is an immunizing event, resulting in protective antibodies that prevent disease. The prevalence of carriage is highly variable. In industrialized countries, meningococcal carriage is observed in roughly $10 \%$ of the population overall, rising from $2 \%$ in children under 4 years to a peak of $24.5 \%-32 \%$ among 15 - to 24 -year-olds, then declining with increasing age. ${ }^{6,7}$ Though carriage prevalence can mirror the overall epidemiology of disease, the relationship between risk factors for disease and those associated with carriage is incompletely understood. Further, carriage prevalence does not predict the incidence of disease nor the occurrence or severity of outbreaks. Even in settings of outbreaks or in hyperendemic disease, nasopharyngeal carriage of diseaseassociated strains may be exceedingly rare. Serogroup and molecular diversity is greater among carried isolates than among invasive isolates. ${ }^{8}$

\section{Correlates of protection against meningococcal disease}

Because of the low incidence of meningococcal disease, prelicensure vaccine efficacy trials employing disease outcomes are not feasible. Meningococcal vaccines are evaluated and licensed based on evidence of an immune response in subjects receiving vaccine using serum bactericidal activity (SBA) as the immunologic correlate of protection. Goldschneider et al demonstrated that serum bactericidal antibody levels correlate with protection against meningococcal disease using human complement (hSBA). Titers of four to eight were shown to confer protection against disease and hSBA has since been considered the gold standard correlate of protection. ${ }^{9}, 10$ In addition, SBA titers of $\geq 128$ using baby rabbit complement (rSBA) have been shown to predict protection in humans. ${ }^{11-13}$ Postlicensure studies in the UK validated these correlates of protection, and additionally proposed that titers between eight and 64 are also likely to be protective. ${ }^{14}$ While these correlates of protection have been evaluated for serogroup $\mathrm{C}$ disease, they have been generally used as correlates of protection for other serogroups. Controversy remains over the "best" complement source, and regulatory agencies have different requirements for testing in prelicensure trials.

\section{Polysaccharide vaccines}

Meningococcal polysaccharide vaccines have been in use since the 1970s. There are several combinations used globally, including bivalent (A,C), trivalent (A,C,W-135), and quadrivalent $(\mathrm{A}, \mathrm{C}, \mathrm{Y}, \mathrm{W}-135)$ vaccines. The effectiveness of capsular polysaccharide vaccines has been demonstrated in military recruits, community outbreaks, and household contacts of affected individuals. ${ }^{15-18}$ Serogroup A vaccines have also been used effectively during outbreaks in Africa. ${ }^{19-21}$

The immunologic characteristics of capsular polysaccharide vaccines limit their impact in preventive vaccination programs. The polysaccharide antigen is T-cell independent and stimulates antibody production in mature B-lymphocytes. Without a T-cell mediated response, there is no class switching, affinity maturation, or development of memory cells. ${ }^{22,23}$ Polysaccharide vaccines are not as effective in infants because infants lack the mature lymphocytes 
required for a robust immune response. Infants vaccinated between 7 and 12 months of age have an SBA concentration indistinguishable from unimmunized children by 24 months of age ${ }^{24}$ and effectiveness rapidly declines to $8 \%$ in children under 4 years of age. ${ }^{25}$ Moreover, revaccination does not induce a booster response and multiple doses may result in hypo-responsiveness to subsequent doses, although the clinical significance of this is unclear. ${ }^{26-28}$ Finally, polysaccharide vaccines do not completely protect from acquisition of nasopharyngeal carriage and therefore they do not provide long-term herd immunity. ${ }^{29,30}$

\section{Conjugate vaccines}

Conjugation of capsular polysaccharides to a protein carrier results in a T-dependent immune response. These carrier proteins are presented by polysaccharide specific B-cells to helper T-cells, enhancing production of plasma cells and memory B-cells. The result is a more robust immune response compared with polysaccharide vaccines, including greater antibody persistence, greater avidity, and long-term immunologic memory. ${ }^{31}$ Conjugate vaccines to respiratory bacterial pathogens are immunogenic in infants, and protect against acquisition of nasopharyngeal carriage. Several formulations of meningococcal conjugate vaccines are currently available (Table 1). Their composition varies greatly and differences in capsular serogroup used, modification of the capsular antigen, type of carrier protein used, and the method of conjugation all can affect the characteristics of the immune response and therefore the effectiveness of the vaccine. Vaccine effectiveness is also dependent on the targeted vaccination group and the dosing schedule. Immune responses and waning immunity are age dependent, with young infants and children requiring more doses and demonstrating more rapid decline in antibody levels compared to older children and adolescents. ${ }^{31}$

The contribution of the memory response to duration of protection of meningococcal vaccines is unclear. Studies suggest that circulating antibody is needed for protection from meningococcal vaccines due to the rapid onset of disease; therefore antibody persistence studies can be used to estimate duration of protection of meningococcal vaccines. ${ }^{32}$ Because vaccine licensure studies rely on short-term immunogenicity as the evaluated outcome, disease surveillance and postlicensure evaluations of meningococcal vaccination programs are critical for determining the most effective vaccination strategies.

\section{Immunogenicity of monovalent serogroup $C$ vaccines}

Meningococcal serogroup C (MCC) vaccines were introduced in the UK in 1999 in response to high rates of serogroup C disease caused by a virulent clone (Table 1$).{ }^{1}$ The safety and immunogenicity of the three different MCC vaccines in children and adults have been demonstrated in several studies, and there are no substantial differences in effectiveness between the vaccine types. ${ }^{33-40}$ Ninety-eight percent of infants develop rSBA titers $\geq 8$, the putative correlate of protection, following a three-dose series at 2, 3, and 4 months of age. ${ }^{33,36-38,41}$ Similar immune responses are seen following a two-dose series at 3 and 5 months as well as a single dose in older children and adults. ${ }^{42-44,47}$

Antibody persistence has been followed closely after MCC vaccination in the UK, and waning immunity is demonstrated, especially in infants and young children. In the absence of a booster dose, only $8 \%-12 \%$ of children completing a three-dose series in infancy had rSBA titers $\geq 8$ at age 4 years. ${ }^{45}$ Among 250 children primed at ages ranging from 2 months to 6 years, only $25 \%$ (95\% confidence interval [CI]: $20 \%-30 \%$ ) had protective rSBA titers $\geq 8$ at 1 year. ${ }^{46}$ Among children who received a single dose of MCC vaccine at age 2 years, $37 \%$ had a titer $\geq 8,2$ years later. ${ }^{48}$ Even following a booster dose in the second year of life only $23 \%-43 \%$ of children maintained protective SBA titers 2 years later. ${ }^{49}$ Waning immunity among adolescents vaccinated with MCC is much less pronounced. In two studies of adolescents vaccinated at age 10 years, $62 \%-75 \%$ of adolescents vaccinated maintained protective hSBA titers $\geq 8$ 3-6 years following vaccination. ${ }^{47,50}$ In a third study, Snape et al found

Table I Meningococcal conjugate vaccine products'

\begin{tabular}{llll}
\hline Vaccine & Manufacturer & Serogroups & Protein conjugate \\
\hline Menveo $^{\text {TM }}$ & Novartis Vaccines & A, C, Y, W-I35 & Diphtheria cross-reactive material I97 (CRM ${ }_{197}$ ) \\
Menactra $^{T M}$ & Sanofi Pasteur & A, C, Y, W-I35 & Diphtheria toxoid \\
Meningitec $^{T M}$ & Wyeth Vaccines & $\mathrm{C}$ & CRM $_{197}$ \\
Menjugate $^{\circledR}$ & Novartis Vaccines & $\mathrm{C}$ & CRM $_{197}$ \\
NeisVac-C $^{\mathrm{TM}}$ & Baxter Bioscience & $\mathrm{C}$ & Tetanus toxoid \\
MenAfriVac $^{\mathrm{TM}}$ & Serum Institute of India & A & Tetanus toxoid \\
\hline
\end{tabular}

'Adapted with permission from Vaccines, 5th ed, Granoff et al, Meningococcal Vaccines, p 399-434, Copyright Elsevier (2008). ${ }^{93}$ 
that 5-year postvaccination GMT titers were significantly greater in children vaccinated after age 10 years than those vaccinated at age $6-10$ years. ${ }^{51}$ These studies suggest that immune maturation may play an important role in duration of protection.

\section{Immunogenicity of quadrivalent serogroup $A, C, Y, W$ - I 35 vaccines}

Two quadrivalent (A, C, Y, W-135) meningococcal conjugate vaccines are licensed in the US (Table 1). While these vaccines are often recommended and used for protection against serogroup A in travelers, the US is the only country that employs a routine program of immunization due to the proportion of meningococcal disease caused by serogroup Y.

Prelicensure trials for MenACWY $\mathrm{D}_{\mathrm{D}}$ demonstrated the safety and immunologic noninferiority to quadrivalent polysaccharide vaccine. At 28 days after a single dose, a similar high proportion of 11- to 18-year-old subjects achieved at least a four-fold rise in rSBA titers, and the proportion achieving rSBA of $\geq 128$ was $>98 \%$ for all serogroups for both vaccines. ${ }^{52}$ Comparable results were demonstrated for adults ages 18 through 55 years, with $>97 \%$ $\mathrm{rSBA} \geq 128$ for all serogroups for both vaccines. ${ }^{53}$ High rates of protective rSBA titers $\geq 128$ were also demonstrated in children aged 2-10 years with levels varying depending on the serogroup ( $81 \%$ for serogroup C to $97 \%$ for serogroup A). ${ }^{54}$

MenACWY ${ }_{\mathrm{CRM}}$ is a second quadrivalent vaccine using diphtheria cross-reactive protein as the carrier protein. A randomized controlled trial conducted among persons aged 11-18 years demonstrated noninferiority of MenACWY $\mathrm{CRM}_{\mathrm{C}}$ compared to MenACWY for all four serogroups. The proportions of subjects with rSBA seroresponse were statistically higher for serogroups A, W-135, and Y in the MenACWY ${ }_{C R M}$ group, compared with the MenACWY group. ${ }^{55}$ Other randomized controlled trials among persons aged 19-55 years and children aged 2-10 years demonstrated similar results. ${ }^{56,57}$ While statistically significant, these differences were small and assays have not been standardized, making direct comparisons somewhat difficult. The clinical relevance of the higher postvaccination immune responses is not known.

The duration of protection following vaccination with quadrivalent meningococcal conjugate vaccines remains an important subject of evaluation. Persistence of protective levels of antibodies 3 years postvaccination as well as immunologic priming have been demonstrated in adolescent recipients of MenACWY are inconsistent and all demonstrate significant declines in antibody levels over 3 years. ${ }^{52,58}$ For serogroup C, geometric mean titers (GMT) declines as much as $90 \%$ over 3 years and the proportion of adolescents with protective antibodies is as low as $30 \%-54 \% .^{52,59}$ The proportion of 2-year-olds with hSBA titers $\geq 46$ months following vaccination was approximately $50 \%$ for serogroups $\mathrm{C}$, Y, and $\mathrm{W}-135{ }^{60,61}$ Similar decline in the duration of protection is seen with MenACWY ${ }_{\mathrm{CRM}}$. At 22 months postvaccination, 34\% (serogroup A) to $84 \%$ (Serogroup W-135) had hSBA $\geq 8 .{ }^{59}$ Concerns of waning immunity prompted the US to recommend a booster dose as part of its adolescent immunization program. ${ }^{62}$

\section{Immunogenicity of monovalent serogroup $A$ conjugate vaccine}

Epidemic meningococcal disease remains a devastating public health problem in the sub-Saharan African meningitis belt, stretching across the Sahel from Senegal to Ethiopia. Annual incidence averages from 25-100 cases per 100,000 persons, and can exceed 1000 cases per 100,000 during peak epidemic years. Serogroup A is the predominant disease- and outbreak-associated serogroup in the region. ${ }^{3}$ Polysaccharide vaccines have been used with some success for many years to limit the extent of disease in outbreak settings. Until recently, fiscal and logistical considerations prevented the development and large-scale introduction of a conjugate vaccine as part of a preventive vaccination program. In 2010, MenAfriVac, a new meningococcal A - tetanus toxoid conjugate vaccine was licensed for persons aged 1-29 years old and prequalified by the World Health Organization for use in Africa. Since September 2010, over 20 million people have been vaccinated in Burkina Faso, Mali, and Niger. This is the first large-scale introduction of a meningococcal conjugate vaccine in Africa. At a price of US\$0.40 per dose, the current strategy of mass vaccination of all 1-29 year olds is within reach of even the poorest countries of the region. Subsequent vaccination of infants, if necessary, will require further mobilization of support from additional donors. ${ }^{63}$

In a published prelicensure trial of 105 adults aged 18-35 years who received one dose of MenA vaccine, $100 \%$ and $92 \%$ of subjects had protective titers by 4 weeks postvaccination by rSBA and hSBA, respectively. Greater than four-fold increases in antibody titers were seen in $83 \%$ and $87 \%$ of subjects, with demonstrated antibody 
persistence at 1 year. Using rSBA assays, $100 \%$ of subjects with a four-fold rise in titers maintained this response at 1 year postvaccination. Protective rSBA titers $\geq 8$ as well as MenA $\operatorname{IgG}>2 \mu \mathrm{g} / \mathrm{mL} 1$ year postvaccination were also seen in $100 \%$ of patients. ${ }^{64,65}$ Data from these trials are similar to that seen in other meningococcal conjugate vaccines. Continued effectiveness studies in the field are ongoing and necessary to evaluate the long-term effect of this vaccine on epidemic meningococcal disease.

\section{Immunologic memory and booster response after meningococcal conjugate vaccination}

Conjugate vaccines elicit immunologic memory, but memory may not play as important a role in protection against meningococcal disease compared to Haemophilus influenza and Strepcococcus pneumoniae. Meningococcal conjugate vaccines prime the immune system and immunologic memory persists even in the absence of detectable bactericidal antibodies. In a study of 4-year-olds in whom postconjugate vaccination titers had declined to prevaccination levels, boosting with meningococcal polysaccharide vaccine resulted in a 1000-fold increase in geometric mean titers and geometric mean avidity index was 1.33 -fold higher 1 month following the vaccine. High GMTs are achieved after boosting following a single primary dose of MCC at 12 months of age. $37,38,43,46,66-70$

A strong association has been noted between MCCspecific antibody levels and the number of memory B cells measured after immunization. This level correlates with antibody persistence at 1 year, suggesting the importance of persistence of functional antibody in long-term humoral immunity. ${ }^{71}$ However, additional studies of the kinetics of antibody responses following boosting show that it takes up to 10 days to achieve protective SBA titers $\geq 8$ in adults. $^{72}$ If antibody presence wanes, this lag may not be rapid enough to protect against infection with $N$. meningitidis, considering the rapid onset of disease. Analyses of breakthrough cases following vaccination have found evidence of priming but low SBA activity. An anamnestic immune response is observed, but is hypothesized not to occur prior to development of invasive disease. ${ }^{32}$

\section{Meningococcal vaccine programs and vaccine effectiveness}

Since routine meningococcal vaccination was introduced in the UK in 1999, vaccination programs have expanded across Europe, Australia, and North America (Table 2). ${ }^{73-79}$ These programs have been implemented using various schedules and target age groups. ${ }^{1,77,78,80,81}$ In general, vaccine effectiveness estimates have paralleled immunogenicity data, but the observed public health impact of these programs is likely a combination of the vaccines used, the target age groups, and the recommended schedule. While some countries have implemented routine recommendations for a specific age group, others have implemented catch-up campaigns in addition to routine recommendations, more rapidly achieving high vaccine coverage and population protection. Differences in circulating strain diversity may also contribute to varying vaccine effectiveness, and postlicensure studies have

Table 2 Global meningococcal conjugate vaccine programs

\begin{tabular}{|c|c|c|c|}
\hline Country & Vaccine product & $\begin{array}{l}\text { Year } \\
\text { introduced }\end{array}$ & Schedule \\
\hline $\mathrm{UK}^{94}$ & Men C Conjugate (MenC) & 1999 & Routine primary series at 3 and 4 mo with booster at $12 \mathrm{mo}$ \\
\hline \multirow[t]{2}{*}{ Canada 95} & Men C & 2002 & Single dose at 12 mo (most provinces) with catch up \\
\hline & Men $\mathrm{ACYW}_{\mathrm{d}}{ }^{2}$ (PEI and NB only $)^{4}$ & 2006 & through age 20 yrs \\
\hline Australia & Men C & 2003 & Single dose at $12 \mathrm{mo}$ \\
\hline \multirow[t]{2}{*}{ USA } & Men $\mathrm{ACWY}_{\mathrm{d}}{ }^{2}$ & 2005 & Single dose at age $1 \mathrm{I}-18$ years; booster dose in 5 years; \\
\hline & Men $\mathrm{ACWY}_{\mathrm{crm}}{ }^{3}$ & 2010 & from age 2 years in certain high risk groups \\
\hline Spain ${ }^{85}$ & Men C & 2000 & $\begin{array}{l}\text { Routine primary series at } 2,4 \text {, and } 6 \text { mo with catch up } \\
\text { through age } 6 \text { yrs ( } 3 \text { provinces through adolescence) }\end{array}$ \\
\hline Ireland 96 & Men C & 2000 & Routine primary series at 4 and 6 mo with booster at 12 mo \\
\hline Netherlands ${ }^{79}$ & Men C & 2002 & I dose at $14 \mathrm{mo}$ \\
\hline Belgium ${ }^{97}$ & Men C & 2002 & I dose at $12 \mathrm{mo}$ \\
\hline Germany ${ }^{97}$ & Men C & 2006 & I dose $12-23 \mathrm{mo}$ \\
\hline Greece $^{75}$ & Men C & 2001 & Single dose at $12 \mathrm{mo}^{5}$ \\
\hline Africa (Burkina, Mali, Niger) & Men A & 2010 & Mass vaccination of I- to 29 -year-olds with single dose \\
\hline
\end{tabular}

Notes: '2, 4, 6 months 1999-2006; ${ }^{2}$ Men A, C, Y, W-I 35 conjugated to diphtheria toxoid; ${ }^{3}$ Men A, C, Y, W-I 35 conjugated to diphtheria cross-reactive material I97; ${ }^{4}$ Prince Edward Island; New Brunswick; ${ }^{5}$ Voluntary participation by providers; may be given up to 14 years.

Abbreviation: mo, months. 
demonstrated the importance of reduction in carriage and herd immunity. ${ }^{84-88}$

In the UK, vaccine effectiveness in adolescents (93\%) was sustained up to 4 years after the catch-up vaccination. While effectiveness was high (83\%) in those receiving catch-up immunization after 5 months of age, it was lower among those vaccinated in infancy $(66 \%) .{ }^{82,83}$ In Spain, vaccine effectiveness greater than 1 year postvaccination was $78 \%$ among those vaccinated in infancy, but 94\% among children ages 7 months -5 years at vaccination. ${ }^{84,85} \mathrm{VE}$ studies in United States are ongoing, but initial estimates suggest vaccine effectiveness wanes to $50 \%-60 \%$ 2-5 years after vaccination. ${ }^{87}$

Conjugate vaccine programs have potential to provide indirect protection through herd immunity. Two years after introduction of $\mathrm{MCC}$ vaccine in the UK, serogroup C carriage was reduced by $67 \% .{ }^{86}$ Attack rates among unvaccinated children in the UK also declined by $67 \%$ in the 4 years following vaccine introduction. Between 1998 and 2009, the incidence of serogroup $\mathrm{C}$ disease in persons over 25 years dropped from 0.55 per 100,000 persons to 0.02 per 100,000 persons; and the number of cases in infants under 3 months of age dropped from 13 in 1998 to one in $2009 .{ }^{88}$ These effects were seen despite a declining seroprevalence of protective antibodies among vaccination cohorts as early as 18 months after the last scheduled dose of vaccine, suggesting sustained protection due to herd immunity despite absence of protective antibodies in individuals. ${ }^{89}$ Additional suggestions of herd immunity come from Ontario, where a $16 \%$ reduction per year in serogroup $\mathrm{C}$ disease occurred among persons $\geq 20$ years of age from 2000-2006 following introduction of an MCC vaccination program in adolescents and infants in $2001 .^{90}$ Herd immunity has not been demonstrated in the United States, where coverage with quadrivalent meningococcal vaccine among adolescents has increased slowly in the 5 years since introduction.

\section{Future directions}

Meningococcal conjugate vaccination programs in the meningitis belt are just beginning and have potential to eliminate epidemic serogroup A meningococcal disease as a public health concern in the region. In 2010, Burkina Faso, Mali, and Niger implemented large-scale vaccination campaigns country or district wide, vaccinating all persons ages $1-29$ years. ${ }^{63}$ Programs of mass vaccination campaigns followed by routine infant or early childhood vaccination were modeled on the successful experience in the UK. As the vaccine is implemented, case-based, laboratory-confirmed surveillance is crucial to evaluating the early long-term impact on both disease and the circulating strains. Special studies are also needed to understand impact on carriage and vaccine effectiveness.

To maximize impact at an acceptable cost is the challenge for meningococcal vaccination programs in industrialized countries. The Advisory Committee on Immunization Practices in the US recently recommended adding a booster dose of MenACWY for all 16-year-olds, 5 years after their initial dose, because early data suggested clinically relevant waning immunity. In contrast, reductions in serogroup $\mathrm{C}$ disease persist over 10 years after the catch-up campaigns in the UK. There is no evidence for strain replacement in England and Wales following implementation of a nationwide conjugate vaccine program. ${ }^{91}$ Nonetheless, there is evidence of increased genetic diversity in strains causing invasive disease in the UK and ongoing surveillance is necessary. ${ }^{92}$ Countries continue to monitor for increases in disease caused by serogroups not in their current vaccination program, and meningococcal vaccination programs will surely adapt to changes in disease patterns in the future.

\section{Disclosure}

No conflicts of interest were declared in relation to this paper.

\section{References}

1. Miller E, Salisbury D, Ramsay M. Planning, registration, and implementation of an immunisation campaign against meningococcal serogroup C disease in the UK: a success story. Vaccine. 2001;20(Suppl 1): S58-S67.

2. Brouwer MC, Tunkel AR, van de Beek D. Epidemiology, diagnosis, and antimicrobial treatment of acute bacterial meningitis. Clin Microbiol Rev. 2010;23(3):467-492.

3. Harrison LH, Trotter CL, Ramsay ME. Global epidemiology of meningococcal disease. Vaccine. 2009;27(Suppl 2):B51-B63.

4. Caugant DA. Population genetics and molecular epidemiology of Neisseria meningitidis. APMIS. 1998;106(5):505-525.

5. Cohn AC, MacNeil JR, Harrison LH, et al. Changes in Neisseria meningitidis disease epidemiology in the United States, 1998-2007: implications for prevention of meningococcal disease. Clin Infect Dis. 2010;50(2):184-191.

6. Cartwright KA, Stuart JM, Jones DM, Noah ND. The Stonehouse survey: nasopharyngeal carriage of meningococci and Neisseria lactamica. Epidemiol Infect. 1987;99(3):591-601.

7. Caugant DA, Høiby EA, Magnus P, et al. Asymptomatic carriage of Neisseria meningitidis in a randomly sampled population. J Clin Microbiol. 1994;32(2):323-330.

8. Claus H, Maiden MC, Maag R, Frosch M, Vogel U. Many carried meningococci lack the genes required for capsule synthesis and transport. Microbiology. 2002;148(Pt 6):1813-1819.

9. Goldschneider I, Gotschlich EC, Artenstein MS. Human immunity to the meningococcus. I. The role of humoral antibodies. J Exp Med. 1969;129(6):1307-1326. 
10. Gotschlich EC, Goldschneider I, Artenstein MS. Human immunity to the meningococcus. IV. Immunogenicity of group A and group C meningococcal polysaccharides in human volunteers. J Exp Med. 1969; 129(6):1367-1384.

11. Santos GF, Deck RR, Donnelly J, Blackwelder W, Granoff DM. Importance of complement source in measuring meningococcal bactericidal titers. Clin Diagn Lab Immunol. 2001;8(3):616-623.

12. Borrow R, Balmer P, Miller E. Meningococcal surrogates of protection - serum bactericidal antibody activity. Vaccine. 2005; 23(17-18):2222-2227.

13. Borrow R, Andrews N, Goldblatt D, Miller E. Serological basis for use of meningococcal serogroup $\mathrm{C}$ conjugate vaccines in the United Kingdom: reevaluation of correlates of protection. Infect Immun. 2001; 69(3):1568-1573.

14. Andrews N, Borrow R, Miller E. Validation of serological correlate of protection for meningococcal $\mathrm{C}$ conjugate vaccine by using efficacy estimates from postlicensure surveillance in England. Clin Diagn Lab Immunol. 2003;10(5):780-786.

15. Gold R, Artenstein MS. Meningococcal infections. 2. Field trial of group C meningococcal polysaccharide vaccine in 1969-1970. Bull WHO. 1971;45(3):279-282.

16. Biselli R, Fattorossi A, Matricardi PM, Nisini R, Stroffolini T, D'Amelio R. Dramatic reduction of meningococcal meningitis among military recruits in Italy after introduction of specific vaccination. Vaccine. 1993;11(5):578-581.

17. Greenwood BM, Hassan-King M, Whittle HC. Prevention of secondary cases of meningococcal disease in household contacts by vaccination. BMJ. 1978;1(6123):1317-1319.

18. Rosenstein N, Levine O, Taylor JP, et al. Efficacy of meningococcal vaccine and barriers to vaccination. JAMA. 1998;279(6):435-439.

19. Miller MA, Wenger J, Rosenstein N, Perkins B. Evaluation of meningococcal meningitis vaccination strategies for the meningitis belt in Africa. Pediatr Infect Dis J. 1999;18(12):1051-1059.

20. Saliou P, Stoeckel P, Lafaye A, Rey JL, Renaudet J. Controlled tests of anti-meningococcal polysaccharide A vaccine in the African Sahel area (Upper Volta and Mali). Dev Biol Stand. 1978;41:97-108. French.

21. Ismail A, Harris S, Granoff D. Serum group a anticapsular antibodies in a Sudanese population immunized with meningococcal polysaccharide vaccine during a group A epidemic. Pediatr Infect Dis J. 2004;23(8): 748-755.

22. Kelly D, Pollard A, Moxon ER. Immunological memory: the role of $\mathrm{B}$ cells in long-term protection against invasive bacterial pathogens. JAMA. 2005;294(23):3019-3023.

23. Kelly D, Snape MD, Clutterbuck EA, et al. CRM197-conjugated serogroup $\mathrm{C}$ meningococcal capsular polysaccharide, but not the native polysaccharide, induces persistent antigen-specific memory B cells Blood. 2006;108(8):2642-2647.

24. Gold R, Lepow ML, Goldschneider I, Draper TF, Gotshlich EC. Kinetics of antibody production to group $\mathrm{A}$ and group $\mathrm{C}$ meningococcal polysaccharide vaccines administered during the first six years of life: prospects for routine immunization of infants and children. J Infect Dis. 1979;140(5):690-697.

25. Reingold AL, Broome CV, Hightower AW, et al. Age-specific differences in duration of clinical protection after vaccination with meningococcal polysaccharide A vaccine. Lancet. 1985;2(8447):114-118.

26. Gold R, Lepow ML, Goldschneider I, Draper TL, Gotschlich EC. Clinical evaluation of group A and group $\mathrm{C}$ meningococcal polysaccharide vaccines in infants. J Clin Invest. 1975;56(6):1536-1547.

27. Borrow R, Joseph H, Andrews N, et al. Reduced antibody response to revaccination with meningococcal serogroup A polysaccharide vaccine in adults. Vaccine. 2000;19(9-10):1129-1132.

28. MacLennan J, Obaro S, Deeks J, et al. Immune response to revaccination with meningococcal $\mathrm{A}$ and $\mathrm{C}$ polysaccharides in Gambian children following repeated immunisation during early childhood. Vaccine. 1999; 17(23-24):3086-3093.

29. Hassan-King MK, Wall RA, Greenwood BM. Meningococcal carriage, meningococcal disease and vaccination. J Infect. 1988;16(1):55-59.
30. Blakebrough IS, Greenwood BM, Whittle HC, Bradley AK, Gilles HM. Failure of meningococcal vaccination to stop the transmission of meningococci in Nigerian schoolboys. Ann Trop Med Parasitol. 1983;77(2):175-178.

31. Pollard AJ, Perrett KP, Beverley PC. Maintaining protection against invasive bacteria with protein-polysaccharide conjugate vaccines. Nat Rev Immunol. 2009;9(3):213-220.

32. Auckland C, Gray S, Borrow R, et al. Clinical and immunologic risk factors for meningococcal $\mathrm{C}$ conjugate vaccine failure in the United Kingdom. J Infect Dis. 2006;194(12):1745-1752.

33. Fairley CK, Begg N, Borrow R, Fox AJ, Jones DM, Cartwright K. Conjugate meningococcal serogroup $\mathrm{A}$ and $\mathrm{C}$ vaccine: reactogenicity and immunogenicity in United Kingdom infants. J Infect Dis. 1996; 174(6):1360-1363.

34. Lieberman JM, Chiu SS, Wong VK, et al. Safety and immunogenicity of a serogroups $\mathrm{A} / \mathrm{C}$ Neisseria meningitidis oligosaccharide-protein conjugate vaccine in young children. A randomized controlled trial. JAMA. 1996;275(19):1499-1503.

35. Lakshman R, Jones I, Walker D, et al. Safety of a new conjugate meningococcal C vaccine in infants. Arch Dis Child. 2001;85(5): 391-397.

36. Bramley JC, Hall T, Finn A, et al. Safety and immunogenicity of three lots of meningococcal serogroup $\mathrm{C}$ conjugate vaccine administered at 2, 3 and 4 months of age. Vaccine. 2001;19(20-22):2924-2931.

37. MacLennan JM, Shackley F, Heath PT, et al. Safety, immunogenicity, and induction of immunologic memory by a serogroup $\mathrm{C}$ meningococcal conjugate vaccine in infants: a randomized controlled trial. JAMA. 2000;283(21):2795-2801.

38. Richmond P, Borrow R, Miller E, et al. Meningococcal serogroup C conjugate vaccine is immunogenic in infancy and primes for memory. J Infect Dis. 1999;179(6):1569-1572.

39. Goldblatt D, Borrow R, Miller E. Natural and vaccine-induced immunity and immunologic memory to Neisseria meningitidis serogroup $\mathrm{C}$ in young adults. J Infect Dis. 2002;185(3):397-400.

40. Choo S, Zuckerman J, Goilav C, Hatzmann E, Everard J, Finn A. Immunogenicity and reactogenicity of a group $\mathrm{C}$ meningococcal conjugate vaccine compared with a group $\mathrm{A}+\mathrm{C}$ meningococcal polysaccharide vaccine in adolescents in a randomised observer-blind controlled trial. Vaccine. 2000;18(24):2686-2692.

41. English M, MacLennan JM, Bowen-Morris JM, et al. A randomised, double-blind, controlled trial of the immunogenicity and tolerability of a meningococcal group $\mathrm{C}$ conjugate vaccine in young British infants. Vaccine. 2000;19(9-10):1232-1238.

42. Schmitt HJ, Steul KS, Borkowski A, Ceddia F, Ypma E, Knuf M. Two versus three doses of a meningococcal $\mathrm{C}$ conjugate vaccine concomitantly administered with a hexavalent DTaP-IPV-HBV/Hib vaccine in healthy infants. Vaccine. 2008;26(18):2242-2252.

43. Borrow R, Goldblatt D, Finn A, et al. Immunogenicity of, and immunologic memory to, a reduced primary schedule of meningococcal C-tetanus toxoid conjugate vaccine in infants in the United Kingdom. Infect Immun. 2003;71(10):5549-5555.

44. Sigurdardottir ST, Davidsdottir K, Arason VA, et al. Safety and immunogenicity of CRM197-conjugated pneumococcal-meningococcal $\mathrm{C}$ combination vaccine $(9 \mathrm{vPnC}-\mathrm{MnCC})$ whether given in two or three primary doses. Vaccine. 2008;26(33):4178-4186.

45. Borrow R, Goldblatt D, Finn A, et al. Antibody persistence and immunological memory at age 4 years after meningococcal group $\mathrm{C}$ conjugate vaccination in children in the United Kingdom. J Infect Dis. 2002;186(9):1353-1357.

46. Perrett KP, Winter AP, Kibwana E, et al. Antibody persistence after serogroup $\mathrm{C}$ meningococcal conjugate immunization of United Kingdom primary-school children in 1999-2000 and response to a booster: a phase 4 clinical trial. Clin Infect Dis. 2010;50(12):1601-1610.

47. Sakou II, Tzanakaki G, Tsolia MN, et al. Investigation of serum bactericidal activity in childhood and adolescence 3-6 years after vaccination with a single dose of serogroup $\mathrm{C}$ meningococcal conjugate vaccine. Vaccine. 2009;27(33):4408-4411. 
48. Snape MD, Kelly DF, Green B, Moxon ER, Borrow R, Pollard AJ. Lack of serum bactericidal activity in preschool children two years after a single dose of serogroup $\mathrm{C}$ meningococcal polysaccharide-protein conjugate vaccine. Pediatr Infect Dis J. 2005;24(2):128-131.

49. Borrow R, Andrews N, Findlow H, et al. Kinetics of antibody persistence following administration of a combination meningococcal serogroup $\mathrm{C}$ and haemophilus influenzae type $b$ conjugate vaccine in healthy infants in the United Kingdom primed with a monovalent meningococcal serogroup C vaccine. Clin Vaccine Immunol. 2010;17(1):154-159.

50. Snape MD, Kelly DF, Salt P, et al. Serogroup C meningococcal glycoconjugate vaccine in adolescents: persistence of bactericidal antibodies and kinetics of the immune response to a booster vaccine more than 3 years after immunization. Clin Infect Dis. 2006;43(11): $1387-1394$.

51. Snape MD, Kelly DF, Lewis S, et al. Seroprotection against serogroup $\mathrm{C}$ meningococcal disease in adolescents in the United Kingdom: observational study. BMJ. 2008;336(7659):1487-1491.

52. Keyserling H, Papa T, Koranyi K, et al. Safety, immunogenicity, and immune memory of a novel meningococcal (groups A, C, Y, and W-135) polysaccharide diphtheria toxoid conjugate vaccine (MCV-4) in healthy adolescents. Arch Pediatr Adolesc Med. 2005;159(10):907-913.

53. Campbell JD, Edelman R, King JC Jr, Papa T, Ryall R, Rennels MB. Safety, reactogenicity, and immunogenicity of a tetravalent meningococcal polysaccharide-diphtheria toxoid conjugate vaccine given to healthy adults. $J$ Infect Dis. 2002;186(12):1848-1851.

54. Pichichero M, Casey J, Blatter M, et al. Comparative trial of the safety and immunogenicity of quadrivalent (A, C, Y, W-135) meningococcal polysaccharide-diphtheria conjugate vaccine versus quadrivalent polysaccharide vaccine in two- to ten-year-old children. Pediatr Infect Dis J. 2005;24(1):57-62.

55. Jackson LA, Baxter R, Reisinger K, et al. Phase III comparison of an investigational quadrivalent meningococcal conjugate vaccine with the licensed meningococcal ACWY conjugate vaccine in adolescents. Clin Infect Dis. 2009;49(1):e1-e10.

56. Reisinger KS, Baxter R, Block SL, Shah J, Bedell L, Dull PM. Quadrivalent meningococcal vaccination of adults: phase III comparison of an investigational conjugate vaccine, MenACWY-CRM, with the licensed vaccine, Menactra. Clin Vaccine Immunol. 2009;16(12): 1810-1815.

57. Halperin SA, Diaz-Mitoma F, Dull P, Anemona A, Ceddia F. Safety and immunogenicity of an investigational quadrivalent meningococcal conjugate vaccine after one or two doses given to infants and toddlers. Eur J Clin Microbiol Infect Dis. 2010;29(3):259-267.

58. Vu DM, Welsch JA, Zuno-Mitchell P, Dela Cruz JV, Granoff DM. Antibody persistence 3 years after immunization of adolescents with quadrivalent meningococcal conjugate vaccine. J Infect Dis. 2006; 193(6):821-828.

59. Gill CJ, Baxter R, Anemona A, Ciavarro G, Dull P. Persistence of immune responses after a single dose of Novartis meningococcal serogroup A, C, W-135 and Y CRM-197 conjugate vaccine (Menveo $\hat{A}^{\circledR}$ ) or Menactra $\hat{A}^{\circledR}$ among healthy adolescents. Hum Vaccin. 2010; 6(11): $881-887$.

60. Granoff DM, Harris SL. Protective activity of group C anticapsular antibodies elicited in two-year-olds by an investigational quadrivalent Neisseria meningitidis-diphtheria toxoid conjugate vaccine. Pediatr Infect Dis J. 2004;23(6):490-497.

61. Granoff DM, Morgan A, Welsch JA. Immunogenicity of an investigational quadrivalent Neisseria meningitidis-diphtheria toxoid conjugate vaccine in 2-year old children. Vaccine. 2005;23(34):4307-4314.

62. Centers for Disease Control and Prevention (CDC). Updated recommendations for use of meningococcal conjugate vaccines - Advisory Committee on Immunization Practices (ACIP), 2010. MMWR Morb Mortal Wkly Rep. 2011;60(3):72-76.

63. Meningitis Vaccine Project. Vaccine introduction strategy. Available at: http://www.meningvax.org/vaccine-introduction.php. Accessed May 24, 2011.
64. Findlow H, Plikaytis BD, Aase A, et al. Investigation of different group A immunoassays following one dose of meningococcal group A conjugate vaccine or A/C polysaccharide vaccine in adults. Clin Vaccin Immunol. 2009;16(7):969-977.

65. Kshirsagar N, Mur N, Thatte U, et al. Safety, immunogenicity, and antibody persistence of a new meningococcal group A conjugate vaccine in healthy Indian adults. Vaccine. 2007;25(Suppl 1):A101-A107.

66. Borrow R, Fox AJ, Richmond PC, et al. Induction of immunological memory in UK infants by a meningococcal $\mathrm{A} / \mathrm{C}$ conjugate vaccine. Epidemiol Infect. 2000;124(3):427-432.

67. Richmond P, Borrow R, Goldblatt D, et al. Ability of 3 different meningococcal $\mathrm{C}$ conjugate vaccines to induce immunologic memory after a single dose in UK toddlers. $J$ Infect Dis. 2001;183(1):160-163.

68. MacLennan J, Obaro S, Deeks J, et al. Immunologic memory 5 years after meningococcal $\mathrm{A} / \mathrm{C}$ conjugate vaccination in infancy. $J$ Infect Dis.2001;183(1):97-104.

69. McVernon J, Maclennan J, Buttery J, Oster P, Danzig L, Moxon ER. Safety and immunogenicity of meningococcus serogroup $\mathrm{C}$ conjugate vaccine administered as a primary or booster vaccination to healthy four-year-old children. Pediatr Infect Dis J. 2002;21(8):747-753.

70. McVernon J, MacLennan J, Pollard AJ, et al. Immunologic memory with no detectable bactericidal antibody response to a first dose of meningococcal serogroup $\mathrm{C}$ conjugate vaccine at four years. Pediatr Infect Dis J. 2003;22(7):659-661.

71. Blanchard Rohner G, Snape MD, Kelly DF, et al. The magnitude of the antibody and memory B cell responses during priming with a proteinpolysaccharide conjugate vaccine in human infants is associated with the persistence of antibody and the intensity of booster response. J Immunol. 2008;180(4):2165-2173.

72. de Voer RM, van der Klis FR, Engels CW, et al. Kinetics of antibody responses after primary immunization with meningococcal serogroup $\mathrm{C}$ conjugate vaccine or secondary immunization with either conjugate or polysaccharide vaccine in adults. Vaccine. 2009;27(50): 6974-6982.

73. Bettinger JA, Scheifele DW, Le Saux N, Halperin SA, Vaudry W, Tsang R; Canadian Immunization Monitoring Program, Active (IMPACT). The impact of childhood meningococcal serogroup C conjugate vaccine programs in Canada. Pediatr Infect Dis J. 2009;28(3): 220-224.

74. Kafetzis DA, Stamboulidis KN, Tzanakaki G, et al. Meningococcal group C disease in Greece during 1993-2006: the impact of an unofficial single-dose vaccination scheme adopted by most paediatricians. Clin Microbiol Infect. 2007;13(5):550-552.

75. Cano R, Larrauri A, Mateo S, Alcalá B, Salcedo C, Vázquez JA. Impact of the meningococcal $\mathrm{C}$ conjugate vaccine in Spain: an epidemiological and microbiological decision. Euro Surveill. 2004;9(7):11-15.

76. Salleras L, Dominguez A, Cardenosa N. Impact of mass vaccination with polysaccharide conjugate vaccine against serogroup $\mathrm{C}$ meningococcal disease in Spain. Vaccine. 2003;21(7-8):725-728.

77. Booy R, Jelfs J, El Bashir H, Nissen MD. Impact of meningococcal C conjugate vaccine use in Australia. Med J Aust. 2007;186(3):108-109.

78. De Greeff SC, de Melker HE, Spanjaard L, Schouls LM, van Derende A. Protection from routine vaccination at the age of 14 months with meningococcal serogroup $\mathrm{C}$ conjugate vaccine in the Netherlands. Pediatr Infect Dis J. 2006;25(1):79-80.

79. Wiese-Posselt M, Hellenbrand W, Siedler A, Mayer C. Universal childhood immunisation with pneumococcal vaccine and meningococcal serogroup C vaccine introduced in Germany. Euro Surveill. 2006; 11(9):E060907.

80. National Advisory Committee on Immunization (NACI). Meningococcal $\mathrm{C}$ conjugate vaccination recommendations for infants. an Advisory Committee Statement (ACS). Can Commun Dis Rep. 2007; 33 (ACS-11):1-12.

81. Bilukha OO, Rosenstein N. Prevention and control of meningococcal disease. Recommendations of the Advisory Committee on Immunization Practices (ACIP). MMWR Recomm Rep. 2005;54(RR-7):1-21. 
82. Trotter CL, Andrews NJ, Kaczmarski EB, Miller E, Ramsay ME. Effectiveness of meningococcal serogroup $C$ conjugate vaccine 4 years after introduction. Lancet. 2004;364(9431):365-367.

83. Ramsay ME, Andrews N, Kaczmarski EB, Miller E. Efficacy of meningococcal serogroup $\mathrm{C}$ conjugate vaccine in teenagers and toddlers in England. Lancet. 2001;357(9251):195-196.

84. Larrauri A, Cano R, García M, Mateo S. Impact and effectiveness of meningococcal $\mathrm{C}$ conjugate vaccine following its introduction in Spain. Vaccine. 2005;23(32):4097-4100.

85. Salleras L, Dominguez A, Cardenosa N. Dramatic decline of serogroup C meningococcal disease in Catalonia (Spain) after a mass vaccination campaign with meningococcal C conjugated vaccine. Vaccine. 2003; 21(7-8):729-733.

86. Maiden MC, Ibarz-Pavón AB, Urwin R, et al. Impact of meningococcal serogroup $\mathrm{C}$ conjugate vaccines on carriage and herd immunity. J Infect Dis. 2008;197(5):737-743.

87. Cohn A. Optimizing the Adolescent Meningococcal Vaccination Program; presented at ACIP, October 2010. Available at: http://www. cdc.gov/vaccines/recs/acip/downloads/mtg-slides-oct10/02-5-meningmcv4.pdf. Accessed July 13, 2011.

88. Campbell H, Andrews N, Borrow R, Trotter C, Miller E. Updated postlicensure surveillance of the meningococcal $\mathrm{C}$ conjugate vaccine in England and Wales: effectiveness, validation of serological correlates of protection, and modeling predictions of the duration of herd immunity. Clin Vaccine Immunol. 2010;17(5):840-847.

89. Trotter CL, Borrow R, Findlow J, et al. Seroprevalence of antibodies against serogroup $\mathrm{C}$ meningococci in England in the postvaccination era. Clin Vaccine Immunol. 2008;15(11):1694-1698.
90. Kinlin LM, Jamieson F, Brown EM, et al. Rapid identification of herd effects with the introduction of serogroup $\mathrm{C}$ meningococcal conjugate vaccine in Ontario, Canada, 2000-2006. Vaccine. 2009; 27(11): 1735-1740.

91. Trotter CL, Ramsay ME, Gray S, Fox A, Kaczmarski E. No evidence for capsule replacement following mass immunisation with meningococcal serogroup C conjugate vaccines in England and Wales. Lancet Infect Dis. 2006;6(10):616-617; author reply 617-618.

92. Diggle MA, Clarke SC. Increased genetic diversity of Neisseria meningitidis isolates after the introduction of meningococcal serogroup C polysaccharide conjugate vaccines. J Clin Microbiol. 2005 43(9): 4649-4653.

93. Granoff DM, Harrison L, Borrow R. Meningococcal vaccines. In: Vaccines. Plotkin S, Orenstein W, Offet P, editors. Philadelphia, PA: Saunders; 2008:399-434.

94. Department of Health. Immunisation against infectious disease - 'The Green Book’. Norwich, UK: TSO; 2006.

95. White CP, Scott J. Meningococcal serogroup C conjugate vaccination in Canada: how far have we progressed? How far do we have to go? Can J Public Health. 2010;101(1):12-14.

96. Royal College of Physicians of Ireland (RCPI). Immunisation guidelines for Ireland: menigococcal infections. Dublinm, Ireland: RCPI. 2008.

97. Network, EUIBIS 2009; Available at: http://www.hpa-bioinformatics org.uk/euibis/meningo/vacc_sched_meningo.htm. Accessed July 13, 2011.
Infection and Drug Resistance

\section{Publish your work in this journal}

Infection and Drug Resistance is an international, peer-reviewed openaccess journal that focuses on the optimal treatment of infection (bacterial, fungal and viral) and the development and institution of preventive strategies to minimize the development and spread of resistance. The journal is specifically concerned with the epidemiology of antibiotic

\section{Dovepress}

resistance and the mechanisms of resistance development and diffusion in both hospitals and the community. The manuscript management system is completely online and includes a very quick and fair peerreview system, which is all easy to use. Visit http://www.dovepress.com/ testimonials.php to read real quotes from published authors. 